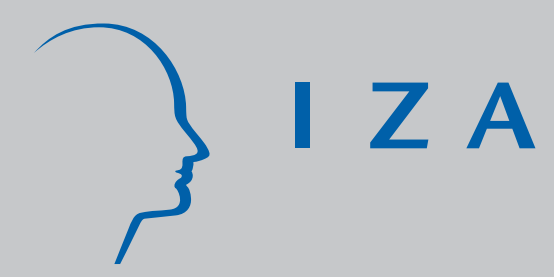

IZA DP No. 3538

Long Term Earnings Inequality, Earnings Instability and Temporary Employment in Spain: 1993-2000

María Cervini Plá

Xavier Ramos

J une 2008 


\title{
Long Term Earnings Inequality, Earnings Instability and Temporary Employment in Spain: 1993-2000
}

\author{
María Cervini Plá \\ Universitat Autònoma de Barcelona \\ Xavier Ramos \\ Universitat Autònoma de Barcelona \\ and IZA
}

Discussion Paper No. 3538

June 2008

IZA

P.O. Box 7240

53072 Bonn

Germany

Phone: +49-228-3894-0

Fax: +49-228-3894-180

E-mail: iza@iza.org

\begin{abstract}
Any opinions expressed here are those of the author(s) and not those of IZA. Research published in this series may include views on policy, but the institute itself takes no institutional policy positions.

The Institute for the Study of Labor (IZA) in Bonn is a local and virtual international research center and a place of communication between science, politics and business. IZA is an independent nonprofit organization supported by Deutsche Post World Net. The center is associated with the University of Bonn and offers a stimulating research environment through its international network, workshops and conferences, data service, project support, research visits and doctoral program. IZA engages in (i) original and internationally competitive research in all fields of labor economics, (ii) development of policy concepts, and (iii) dissemination of research results and concepts to the interested public.
\end{abstract}

IZA Discussion Papers often represent preliminary work and are circulated to encourage discussion. Citation of such a paper should account for its provisional character. A revised version may be available directly from the author. 


\section{ABSTRACT}

\section{Long Term Earnings Inequality, Earnings Instability and Temporary Employment in Spain: 1993-2000*}

This paper provides a longitudinal perspective on changes in Spanish male earnings inequality for the period 1993-2000, by decomposing the earnings covariance structure into its permanent and transitory parts. According to the Spanish sample of the European Community Household Panel, cross-sectional earnings inequality of male full-time employees falls over the second half of the Nineties. The longitudinal analysis shows that such decline was determined by a decrease in earnings instability and an increase of the permanent earnings component. Given the marked decline in temporary employment over the sample period, we also examine the effect of the type of contract on earnings variance components, and we find that workers with fixed-term contract have on average more instability than workers with permanent contract. This evidence suggests that the decline in temporary employment is responsible for the decreasing earnings instability.

JEL Classification: $\quad$ C23, D31, J31

Keywords: earnings dynamics, permanent and transitory differences, earnings instability, covariance structure, minimum distance, temporary employment, Spain

Corresponding author:

Xavier Ramos

Departament d'Economia Aplicada

Universitat Autònoma de Barcelona

Edifici B

08193 Bellaterra

Spain

E-mail: xavi.ramos@uab.es

\footnotetext{
* We would like to thank José María Labeaga, David Pujolar, Hèctor Sala and Lorenzo Cappellari for their very helpful comments. We are grateful to participants at 2006 EALE Conference in Prague for helpful comments on a previous version of this paper. Financial support from the Instituto de Estudios Fiscales and from projects SEJ2004-07373-C03-01/ECON, SEJ2007-67911-C03-02/ECON (Ministerio de Ciencia y Tecnologa), 2005SGR-117 and XREPP (Direcció General de Recerca) is gratefully acknowledged.
} 


\section{Introduction}

Following the early contribution of Lillard and Willis (1978), several studies have more recently analyzed the structure of earnings inequality over time to find out whether observed annual earnings differentials are driven by earnings differences that persist over time or rather reflect earnings instability. $\left.\right|^{1}$ Empirical studies for North America and several European countries, typically find that both earnings components are important to explain recent trends in earnings inequality.

The distinction between permanent and transitory earnings component is important for several reasons. It provides information to help evaluate the various arguments which have been proposed in order to explain increases in earnings inequality in anglosaxon countries. For instance, skill-biased technological change or demand shifts that benefit the highly paid would be consistent with increased earnings inequality being accounted for mostly by persistent differentials. On the contrary, large earnings instability would provide support to explanations favouring the decline of worker-firm attachment, possibly due to increased outsourcing or decreased employment protection legislation (Haider (2001)).

From a policy perspective, the degree of persistence in individual earnings differences also tells us to what extent low earnings is a lasting or a one-off experience. The effectiveness of policies aimed at low-income households can differ substantially depending on whether they face temporary or long-term poverty situations. Whereas earnings volatility may be targeted by correcting market imperfections, long-term inequality suggests the need for intervention aimed at increasing the long-term earnings potential of the low paid, such as active labour market policies (e.g. training programs).

This paper examines the longitudinal features of Spanish earnings inequality and provides information on the relative importance of long-term earnings inequality and earnings instability in a period with stable earnings inequality but important institutional changes in the labour market. In particular, key Employment Protection

\footnotetext{
${ }^{1}$ Some recent contributions are Dickens (2000), Kalwij and Alessie (2003) and Ramos (2003) for Britain; Moffitt and Gottschalk (1995, 2002) Baker (1997) and Haider (2001) for the United States; Baker and Solon (2003) for Canada; Biewen (2005) for Germany and Cappellari (2004) for Italy. Prior to these studies, and with the exception of Abowd and Card (1989), the literature on the covariance structure of earnings jumps back to the late 1970s and early 1980s: Lillard and Willis (1978); Lillard and Weiss (1979); McCurdy (1982).
} 
Legislation (EPL) provisions were substantially changed with the aim of reducing the very large incidence of temporary employment. As a result, the share of temporary employment fell from an all time high $35 \%$ in 1995 to $32 \%$ by the end of our sample period (see Kugler, Jimeno, and Hernanz (2002)). Over the last three decades, many European countries relied on changing EPL to combat the rise in unemployment. Because of that, many of the labour market consequences of changing EPL have attracted the attention of the profession -see the two featured numbers of the Economic Journal of June 2002 and 2007 for recent contributions. However, the often presumed positive association between lower EPL and earnings instability remains largely unexplored (but see Cappellari and Leonardi (2006)). We also examine the relationship between temporary employment and earnings instability and investigate the extent to which changes in temporary employment are responsible for the estimated changes in earnings instability.

We decompose individual earnings into its permanent and transitory components by fitting error component models to the covariance structure of individual earnings. ${ }^{2}$ For this purpose we use the eight waves of the Spanish component of the European Community Household Panel (ECHP). Our findings suggest that earnings instability may have decreased over the period; thus increasing earnings persistence. The latter increases over the life-cycle, which implies lower instability for older cohorts, and accords with most international evidence. We also find larger earnings instability and lower long-term inequality for temporary contract workers, which suggests that the reduction in temporary employment may have contributed to the estimated fall in earnings instability over the second half of the Nineties.

The rest of the paper is structured as follows. The next section describes the data and our methodological decisions. Section 3 presents relevant evidence on earnings statics and dynamics. Section 4 contains a discussion of the error components models. Section 5 presents our main empirical results. Section 6 examines the relationship between type of contract and earnings instability. Finally, section 7 summarizes the main findings and suggests avenues for further research.

\footnotetext{
${ }^{2}$ Cutanda (2002) tries to identify the permanent and transitory components of income inequality in Spain from cross-section data by exploiting the distinct effect that transitory shocks should have on consumption and income dispersion under the life-cycle hypothesis (Blundell and Preston (1998)).
} 


\section{Data and methodological decisions}

The dynamic nature of the analysis requires longitudinal data. We employ the eight waves of the Spanish component of the ECHP, covering the period 1993-2000 3

As most previous studies, we analyze only males. This allows mitigating issues of endogenous female labour market participation, which may be exacerbated when analyzing earnings dynamics. In particular, the sample is restricted to full-time male employees who reported positive earnings in at least one of the eight waves. Therefore, individuals are allowed to enter the panel at any wave and to re-enter the panel if they do exit. Such a sample selection produces an unbalanced panel since not all persons are present for all eight waves. Movements into and out of the sample may be due to unemployment, retirement, mobility to or from self-employment and attrition. The use of the unbalanced panel helps mitigate the potential overestimation of earnings persistence that would arise from balanced samples in which only individuals with positive earnings in each wave contribute to estimation.

To separate life-cycle from time effects, we partition the sample into four age cohorts. $4^{4}$ The youngest cohort contains males born after 1964, i.e. aged less than 31 in 1994. The middle cohorts contain those born between 1954 and 1963, and between 1944 and 1953. The oldest cohort comprises those individuals born before 1943, so aged 50 years or more in 1994 when wave 1 takes place.

Furthermore, we select male workers aged between 21 and 60, so the chosen age range selects out the extremes of the earnings life cycle, where volatility arising just after labour market entry or before retirement may be confounded with volatility due to structural labour market changes. The final sample consists of 5,268 individuals and a total of 20,605 individual-year observations.

The earnings measure is the log of the gross annual earnings or salary, deflated

\footnotetext{
${ }^{3}$ The ECHP is a specially conducted survey and belongs to the ever more complete set of harmonized statistical operations for European Union (EU) countries. ECHP uses fixed panel techniques for 8 annual cycles. The population scope is the private households who live in main family dwellings and the set of people who are members of the household. In the case of Spain, the geographic scope is national with the exception of Ceuta and Melilla. The collection method is personal and phone interviews. Although the ECHP questionnaires cover the period 1994-2001, our sample period is 1993-2000 because the earnings questions refer to the year prior to the interview.

${ }^{4}$ Ideally, we would like to consider one age cohort per year of birth. However, because of the small simple size, we group individuals born in different years into the same cohort. In other words, we chose this level of disaggregation to ensure that there are sufficient observations in each cohort to make the analysis meaningful.
} 
Figure 1: Earnings inequality in Spain 1993-2000

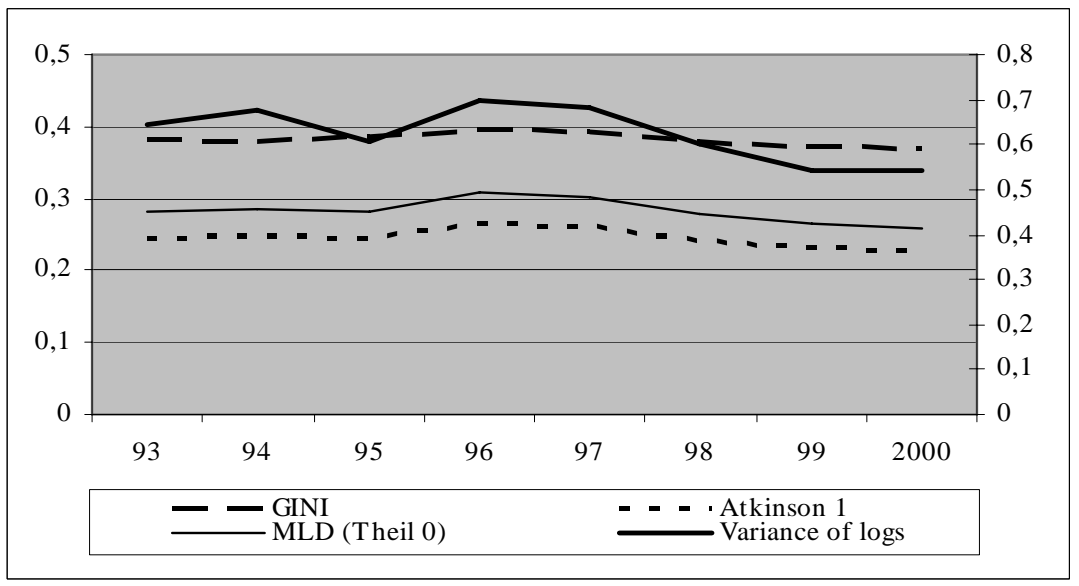

Note: Variance of logs depicted against secondary axis. Source: ECHP, own calculations.

by the consumer price index. Our strategy is to work with log-earnings as individual specific deviation from the mean. 5

\section{Description of earnings differences}

According to standard inequality measures (see Figure 1), cross-section earnings inequality displays a flat trend over the sample period, increasing in the first half of the period and decreasing thereafter. Such a cross-section picture, however, does not tell us anything about the dynamics of individual earnings or about the relative importance of the permanent and transitory components of earnings. In order to analyze the dynamics of individual earnings and to assess the extent to which earnings differences may persist over time, we estimate the covariance matrix of the log-earnings for each cohort. Covariance matrices contain 144 unique elements ( 8 variances and 28 covariances for each one of the four cohorts) $]^{6}$

For all cohorts the covariances are positive and quite large in magnitude relative to the variances. They fall quite sharply for the first couple of lags and then appear to asymptote to a long run level at longer lags. This is consistent with the presence of a permanent individual component of earnings and a transitory component that

\footnotetext{
${ }^{5}$ The same strategy is followed by Baker and Solon (2003) and Cappellari (2004)

${ }^{6}$ For a detailed technical description of how to estimate covariance matrices with an unbalanced panel see the Technical Appendix in Dickens (2000). Covariance matrices for each cohort are available from the authors.
} 
is serially correlated. In addition, the relative magnitudes of the covariances differ across cohorts; the ratio of the longer lag covariances to the variances is smaller for the younger cohorts than for the older cohorts.

\section{Error component models}

The purpose of this section is to present some parsimonious error component models that will characterize the dynamic structure of individual earnings. Let us begin with the simplest model of all, which, despite its simplicity, provides a very intuitive insight into the matter of concern. However, since this first model overlooks several important features of the earnings dynamics, we later on discuss and employ a more general model.

Let $Y_{i c t}$ denote the log earnings in year $t$ of the $i$ th sample member belonging to cohort $c$. Then,

$$
Y_{i c t}=\mu_{c t}+y_{i c t}
$$

expresses $Y_{i c t}$ as the cohort-specific mean $\mu_{c t}$ in the year $t$ plus an individual specific deviation from that mean, $\left.y_{i c t}\right]^{7}$ The most rudimentary error component model is the canonical permanent-transitory model with a white-noise transitory component,

$$
y_{i c t}=\alpha_{i c}+v_{i c t}
$$

where $y_{i c t}$ is expressed as the sum of a time-invariant earnings component $\alpha_{i c}$ with population variance $\sigma_{\alpha}^{2}$, and a time-varying transitory component $v_{i c t}$ with variance $\sigma_{v}^{2}$. The transitory component is assumed to be serially uncorrelated, and $\alpha_{i c}$ and $v_{i c t}$ are orthogonal to each other. The covariance of earnings is determined by:

$$
\operatorname{Cov}\left(y_{i t}, y_{i s}\right)= \begin{cases}\sigma_{\alpha}^{2}+\sigma_{v}^{2} & t=s \\ \sigma_{\alpha}^{2} & t \neq s\end{cases}
$$

The variance of current relative earnings $y_{i c t}$ is $\sigma_{\alpha}^{2}+\sigma_{v}^{2}$, which exceeds $\sigma_{\alpha}^{2}$, the variance in the permanent component of earnings, by $\sigma_{v}^{2}$, the variance of transitory earnings. The variance of the permanent component, $\sigma_{\alpha}^{2}$, (which fully determines

\footnotetext{
${ }^{7}$ Some previous studies have tried to partial out $\mu_{c t}$ with first-stage regressions that take account of year and age effects. We do not pursue this strategy here.
} 
the covariances) represents the persistent dispersion of earnings, and the individual component $\alpha_{i c}$ is seen as representing the effects of (unmeasured) characteristics such as ability and work-related tastes which are assumed to persist throughout the sample period.

However, this rudimentary model possesses several weaknesses that renders it inappropriate for our purposes. First, several empirical studies have found evidence of persistent heterogeneity across individuals, not only in their levels of earnings, but in their growth rates 8 Second, some earnings shocks have permanent effects, and some of the more recent literature on earnings dynamics has modelled such earnings variation with a random-walk component. 9 Third, most studies have found that the transitory component is serially correlated. 10

The following specification extends the simple model in (2) and encompasses all the relevant aspects of earnings dynamics considered above:

$$
y_{i c t}=p_{t} g_{c}\left[\alpha_{i c}+\eta_{i} a_{i c t}+u_{i c t}\right]+\lambda_{t} s_{c} v_{i c t}
$$

where

$$
\begin{gathered}
u_{i c t}=u_{i(c-1)(t-1)}+r_{i c t} \\
\sum_{j=0}^{p} \rho_{j} v_{i c t-j}=\sum_{j=0}^{q} \theta_{j} \varepsilon_{i c t-j}
\end{gathered}
$$

The variance of individual earnings could change with age or labour market experience. Therefore, apart from allowing for permanent individual differences in the level of (log) earnings, one may also allow for different growth rates in earnings across individuals. In equation 4, $a_{i c t}$ is the age of individual $i$ at time $t$ and $\eta_{i}$ is the random growth term with mean 0 and variance $\sigma_{\eta}^{2}$. The intercept $\alpha_{i c}$ represents earnings capacity at the beginning of the working life, determined by schooling or other timeinvariant ability shifters. The growth parameter, $\eta_{i}$, captures idiosyncratic earnings capacity related to age (or experience). For example, in a human capital framework

\footnotetext{
${ }^{8}$ See Hause (1980), Baker (1997), Dickens (2000), Moffitt and Gottschalk (2002), Ramos (2003), Baker and Solon (2003), Kalwij and Alessie (2003), Cappellari (2004).

${ }^{9}$ See Dickens (2000), Moffitt and Gottschalk(1995, 2002), Ramos (2003), Baker and Solon (2003), Kalwij and Alessie (2003), Cappellari (2004).

${ }^{10}$ Several studies fit an ARMA(1,1) -Dickens (2000), Moffitt and Gottschalk(1995, 2002), Biewen (2005)-, while some others model it as a first-order autoregresive process, AR(1), -Baker and Solon (2003), Ramos (2003), Cappellari (2004).
} 
it may result from differential learning ability on-the-job 11 A negative covariance between $\alpha_{i}$ and $\eta_{i}$ implies that the two sources of heterogeneity offset each other, as could be the case in the presence of investments in (generic) on-the-job training (see Hause (1980)). Alternatively, a positive $\sigma_{\alpha \eta}$ implies rising permanent inequality over the life-cycle, which is consistent with schooling-matching models, where more educated workers have higher initial earnings and where in addition these grow faster as the quality of the match is revealed to employers -partly due to their higher propensity to acquire skills on the job.

The returns to human capital may have changed over time as a result of permanent shocks. A simple way to incorporate such non-stationary pattern of earnings is by employing year-specific factor loadings on the permanent and transitory components of relative earnings, $p_{t}$ and $\lambda_{t}$. An increase in $p_{t}$ increases the spread of the earnings distribution but does not affect the ranking of individuals. Then, if the variance of the transitory component does not change, an increase in $p_{t}$ decreases wage mobility.

Since earnings shocks may have permanent effects, equation 5 specifies a randomwalk component in earnings growth, where $r_{i c t}$ is a "white noise" innovation with variance $\sigma_{r}^{2}$. The random-walk innovation $r_{i c t}$, unlike the transitory innovation $\varepsilon_{i c t}$ in equation 6, accommodates any permanent reordering of workers in the earnings distribution.

Cohort shifters $g_{c}$ and $s_{c}$ allow for earnings and its components to vary according to the different life-cycle stage in which they are observed and help distinguish life cycle dynamics from secular changes in earnings inequality.

Finally, equation 6 incorporates serial correlation of the transitory component, $v_{i c t}$ is assumed to follow an $\operatorname{ARMA}(\mathrm{p}, \mathrm{q})$ process and $\varepsilon_{i c t}$ is assumed to be white noise, i.e. serially independently distributed error term with mean 0 and variance $\sigma_{\varepsilon}^{2}$. The autoregressive parameters are denoted by $\rho_{j}$ with $\rho_{0}=1$ and the moving average parameters are denoted by $\theta_{j}$ with $\theta=0$. The parameter $\rho_{j}$ captures the smooth decline of covariances as the lag length increases. ${ }^{12}$

\footnotetext{
${ }^{11}$ Other theoretical frameworks, such as signalling, matching or contract theory also predict earnings heterogeneity at the start of the life cycle and during the career.

${ }^{12}$ As Lillard and Willis (1978) express, this serial correlation term may be interpreted in a couple of ways. First, it reflects the effect of random shocks which persist longer than one year but which deteriorate in effect over time. Second, it reflects the operation of individual, unobservable variables which are serially correlated over time.
} 


\section{Empirical Results}

This section presents the results of fitting the general error component models outlined in the previous section to the elements of the covariance matrix for all four cohorts pooled together (i.e. the 144 auto-covariances), and analyses the changes in the permanent and transitory components over the sample period.

The parameters of the error component models are estimated using minimum distance techniques. The parameters chosen are those that minimize the (weighted) sum of the squared distance between the covariance structure implied by the error component model and the actual covariances 13

Goodness of fit is assessed, and nested models are tested using the sum of squared residuals (henceforth SSR) weighted by the inverse of the estimated variance of residuals. Under the null of correct specification, the SSR statistic is distributed as a chi square with $\left(\Sigma_{c}(t(t+1)-p)\right.$ degrees of freedom, where $\Sigma_{c}$ is the number of cohorts (in our case 4), $t$ is the number of waves and $p$ is the number of parameters.

We have followed a general to specific modelling strategy where, in the case of nested models, the restrictions imposed by more parsimonious models are tested. Here we only present the models which show a better fit. The first two columns of Table 1 present parameter estimates of one of our preferred models:

$$
\begin{gathered}
y_{i c t}=p_{t} g_{c}\left[\alpha_{i c}+\eta_{i} a_{i c t}\right]+s_{c} v_{i c t} \\
\text { where }\left(\alpha_{i}, \eta_{i}\right) \sim\left[(0,0) ;\left(\sigma_{\alpha}^{2}, \sigma_{\eta}^{2}, \sigma_{\alpha \eta}\right)\right] \\
v_{i c t}=\rho_{1} v_{i c t-1}+\lambda_{t} \varepsilon_{i c t} \\
\text { with } \varepsilon_{i c t} \sim\left(0, \sigma_{\varepsilon}^{2}\right) \text { and } v_{i c t} \sim\left(0, \sigma_{0, \text { cohort } \ldots}^{2}\right)
\end{gathered}
$$

This specification is similar to the model represented by equations (4), (5) and (6) in Section 4, without a random walk in the permanent component and with the time shifter of the transitory component applying only to the white noise error term. The permanent component is specified as a random growth in age and the transitory component follows an $A R(1)$ process with cohort-based heteroscedastic initial variances,

\footnotetext{
${ }^{13}$ For a detailed description of the statistical methodology employed to estimate the models see Abowd and Card (1989), Dickens (2000), Cappellari (2004). Following Altonji and Segal (1996), we use the identity matrix as a weighting matrix.
} 
and time- and cohort- specific loading factors on both components. The model is very similar to Cappellari (2004)'s model for the case of Italy.

The estimated coefficients for the long-term earnings component indicate that both time-invariant and age-related heterogeneity matter for the formation of long-term earnings differentials. The estimates of $\sigma_{\alpha}^{2}$ and $\sigma_{\eta}^{2}$ in the first two rows, capture the individual heterogeneity in the intercept and slope of the age-earnings profile. Our estimate of $\sigma_{\eta}^{2}$ implies that a worker with an earnings growth rate one standard deviation above the mean accumulates a $15 \%$ earnings advantage in ten years. ${ }^{14}$

The negative estimate of $\sigma_{\alpha \eta}$ indicates a trade-off between initial earnings and subsequent earnings growth; that is, consistent with the on-the-job-training hypothesis, individual age-earnings profiles seem to cross at relatively early stages of the working career. This is also the evidence found in several previous studies ${ }^{15}$

The estimates of the time-specific loading factors on the permanent component, $p_{t}$, are typically close to 1 . However, the time shifters tend to reproduce the inverted u-shape trend characterizing cross-sectional differentials. First increase with respect to 1994, then decrease sharply in the recovery of the Spanish economy until 1999 where the coefficient remains rather constant and close to 1 again 16 This suggests that the persistent component plays an important role in explaining the rather stable earnings inequality over the sample period.

The estimated cohort-specific loading factors, $g_{\text {cohort }}$, indicate that the persistent component increases over the life-cycle, but for the oldest cohort.

The second panel of Table 1 reports the estimated parameters for the transitory component. The estimates of the initial variances, which capture the accumulation of the transitory process up to the start of the sample period for each cohort, show that they are most important for the older cohorts (with the exception of the oldest cohort, for which the t-ratio is rather low). Thus, initial variances contribute to the cohort-related heteroscedasticity in the transitory component.

The rather small serial correlation parameter estimate $(\rho=0,58)$ implies that the effect of random shocks dies out very quickly, becoming negligible after five years: only

\footnotetext{
${ }^{14}$ The estimate of $\sigma_{\eta}^{2}$ is 0.0002 so, $\sqrt{0.0002}=0.01414 \rightarrow 1.01414^{10}=15.07 \%$.

${ }^{15}$ Lillard and Weiss (1979), Hause (1980), Baker (1997) and Ramos (2003). But see Cappellari (2004) for the opposite result.

${ }^{16}$ For identification, $p_{t}$ for 1993 (wave 1), $\lambda_{t}$ for 1993 and 1994, and $g_{\text {cohort }}$ and $s_{\text {cohort }}$ for the youngest cohorts are all set to 1 .
} 
6.8 percent of a shock to the transitory component is still present after five years. ${ }^{17}$

Not surprisingly, the time-specific loading factors on the transitory innovation display a much larger variation than the corresponding loading factors for the persistent component. They help accommodate the movements observed in actual variances: their relative decline for 1996 and for the last three years of the sample closely follows the trend of the observed variance.

Finally, the estimated cohort-specific loading factors on the transitory component, $s_{\text {cohort..., }}$ are smaller than 1 and they decrease very rapidly as older cohorts are considered, indicating that earnings volatility tends to be larger for younger cohorts. This confirms a pattern already emerged in section 3, where covariances were found to be lower for younger cohorts.

The parameter estimates can be used to predict the permanent and transitory components, thereby providing insights into the extent to which changes in the distribution of life-time earnings and transitory fluctuations contribute to the evolution of cross-sectional differentials. Figure 2 presents the actual and predicted variances of log-earnings by cohort. Permanent and transitory components are predicted setting transitory and permanent weights, respectively, to their 1993 values. It is worth noting that this model is able to reproduce very closely the evolution of the observed variance for each cohort over the sample period.

Earnings inequality -as measured by the actual variance- declines over the sample period for all cohorts except for the oldest one. This trend is mostly accounted for by the evolution of the transitory component. Such reduction in earnings instability is likely to be related to the countervailing labour market reforms of 1994 and 1997, which granted more stability to temporary employment contracts, and to the subsequent decline in temporary employment.

\footnotetext{
${ }^{17}$ That is: $0.5834^{5}=0.0678$.
} 
Table 1: Estimates of earnings dynamic models

\begin{tabular}{|c|c|c|c|c|c|c|}
\hline & \multicolumn{2}{|c|}{$\overline{R G}+\mathbf{A R}(\mathbf{1})$} & \multicolumn{2}{|c|}{$\begin{array}{l}\mathbf{R G}+\mathbf{A R}(\mathbf{1}) \\
+\sigma_{0, \text { cohort } \ldots}^{2}=\sigma_{0}^{2}\end{array}$} & \multicolumn{2}{|c|}{$\begin{array}{l}\mathbf{R G}+\operatorname{ARMA}(\mathbf{1 , 1}) \\
+\sigma_{0, \text { cohort } \ldots}^{2}=\sigma_{0}^{2}\end{array}$} \\
\hline & \multicolumn{6}{|c|}{ Permanent component } \\
\hline & Coefficient & $t$-ratio & Coefficient & $t$-ratio & Coefficient & $t$-ratio \\
\hline$\sigma_{\alpha}^{2}$ & 0.5245 & 3.01 & 0.4797 & 3.41 & 0.452 & 3.11 \\
\hline$\sigma_{\eta}^{2}$ & 0.0002 & 1.71 & 0.0002 & 1.94 & 0.0001 & 1.69 \\
\hline$\sigma_{\alpha \eta}^{2^{T}}$ & -0.0098 & -2.09 & -0.0081 & -2.29 & -0.0074 & -2.03 \\
\hline$p_{94}$ & 0.947 & 24.44 & 0.9261 & 23.93 & 0.9138 & 21.57 \\
\hline$p_{95}$ & 1.0016 & 34.89 & 0.9924 & 33.41 & 0.988 & 31.64 \\
\hline$p_{96}$ & 1.0545 & 29.22 & 1.0557 & 28.68 & 1.0555 & 27.35 \\
\hline$p_{97}$ & 1.0667 & 28.43 & 1.0801 & 29.12 & 1.0795 & 27.7 \\
\hline$p_{98}$ & 0.9876 & 19.43 & 1.0117 & 20.46 & 1.0177 & 19.61 \\
\hline$p_{99}$ & 1.0098 & 14.68 & 1.0466 & 16.34 & 1.0616 & 15.73 \\
\hline$p_{00}$ & 0.9911 & 11.85 & 1.0324 & 13.35 & 1.0474 & 13.13 \\
\hline$g_{(54-63)}$ & 1.4594 & 6.35 & 1.5751 & 7.33 & 1.5637 & 7.15 \\
\hline$g_{(44-53)}$ & 1.6878 & 3.22 & 2.1366 & 3.67 & 2.1315 & 3.64 \\
\hline \multirow[t]{3}{*}{$g_{(<1943)}$} & 1.4629 & 2.43 & 2.0583 & 2.72 & 2.0972 & 2.66 \\
\hline & \multicolumn{6}{|c|}{ Transitory component } \\
\hline & Coefficient & $t$-ratio & Coefficient & $t$-ratio & Coefficient & $t$-ratio \\
\hline$\sigma_{\varepsilon}^{2}$ & 0.068 & 3.18 & 0.0646 & 2.96 & 0.6178 & 6.08 \\
\hline$\sigma_{0}^{2}$ & & & 0.4147 & 6.22 & 0.415 & 6.34 \\
\hline$\sigma_{0,>1964}^{2}$ & 0.386 & 5.21 & & & & \\
\hline$\sigma_{0,54-63}^{2}$ & 0.4381 & 2.13 & & & & \\
\hline$\sigma_{0,44-53}^{2}$ & 1.0607 & 2.98 & & & & \\
\hline$\sigma_{0,<1943}^{2}$ & 0.2924 & 1.49 & & & & \\
\hline$\rho$ & 0.5834 & 5.43 & 0.5841 & 5.51 & 0.2732 & 3.59 \\
\hline$\theta$ & & & & & -0.1354 & -2.7 \\
\hline$\lambda_{95}$ & 0.7165 & 8.62 & 0.7177 & 8.77 & 0.6931 & 8.39 \\
\hline$\lambda_{96}$ & 0.9026 & 8.69 & 0.8986 & 8.8 & 0.8929 & 8.51 \\
\hline$\lambda_{97}$ & 0.805 & 8.77 & 0.7993 & 8.84 & 0.7841 & 8.55 \\
\hline$\lambda_{98}$ & 0.7554 & 8.71 & 0.7465 & 8.73 & 0.7309 & 8.25 \\
\hline$\lambda_{99}$ & 0.6488 & 8.11 & 0.6384 & 8.08 & 0.6127 & 7.4 \\
\hline$\lambda_{00}$ & 0.6296 & 8.42 & 0.6266 & 8.47 & 0.6079 & 7.83 \\
\hline$s_{(54-63)}$ & 0.59 & 16.26 & 0.5934 & 15.68 & 0.5951 & 15.72 \\
\hline$s_{(44-53)}$ & 0.508 & 12.94 & 0.5538 & 13.99 & 0.5562 & 14.15 \\
\hline$s_{(<1943)}$ & 0.4359 & 6.49 & 0.4284 & 6.26 & 0.4334 & 6.3 \\
\hline $\mathrm{SSR} \sim \chi^{2}(d . f)$ & 529.98 & (116) & 526.24 & (119) & 541.92 & (118) \\
\hline
\end{tabular}


A closer look by cohorts reveals that transitory differences account for most of the earnings dispersion only for the youngest one, which is consistent with the disproportionate incidence that temporary employment has on younger workers. ${ }^{18}$ As the age group that suffers most from temporary employment, the observed large fall in overall earnings dispersion -the largest of all cohorts- may perfectly be a reflection of the decline in the transitory component (see Figure 3) -Section 6 addresses this issue by employing an extension of the model, which takes account of the type of contract.

Long-term inequality appears to be at higher levels for older cohorts relative to younger ones, which is consistent with the evidence of life cycle earnings divergence provided earlier. In addition, the incidence of long-term variance on overall inequality tends to be larger the older the cohort considered, reflecting lower volatility.

Our results are similar to those in Baker and Solon (2003), who find that the persistent component has played at least a somewhat larger role in Canada. For Italy, Cappellari (2004) finds that inequality trends have been driven by the long-term earnings component. The reported Spanish earnings mobility patterns across cohorts are also in line with previous studies, where transitory differences appear to fall over the life cycle, being especially high for younger age groups. Finally, the reported moderate degree of persistence of the transitory shocks is not at odds with previous estimates.

Given the similar size of several estimated cohort-specific initial variances, we next test whether the initial heteroscedasticity is statistically defensible with the Spanish data and analyze the implications for the earnings components. Columns 3 and 4 of Table 1 present the results of assuming homoscedastic initial conditions (i.e. $\sigma_{0,>1964}^{2}=$ $\left.\sigma_{0,54-63}^{2}=\sigma_{0,44-53}^{2}=\sigma_{0,<1943}^{2}=\sigma_{0}^{2}\right)$, while keeping the random growth specification of the permanent component. A Wald test on this restriction does not reject the null that initial variances are all the same $\left(\chi^{2}=3.74\right.$ and 4 degrees of freedom $)$. Relative to the previous model, the most noticeable change is the increase in the cohort-specific loading factors of the permanent component. The relative contribution of the permanent and transitory components to the total variance is very similar to that obtained in the previous model.

The models used in previous studies typically impose zero restrictions on the time

\footnotetext{
${ }^{18}$ As many as $57.22 \%$ hold temporary contracts in the youngest cohort. This figure is $25.5 \%, 18.3 \%$ and $17.5 \%$ for the second, third and oldest cohort respectively.
} 
Figure 2: Actual and predicted variances with permanent and transitory predicted components, by cohort.
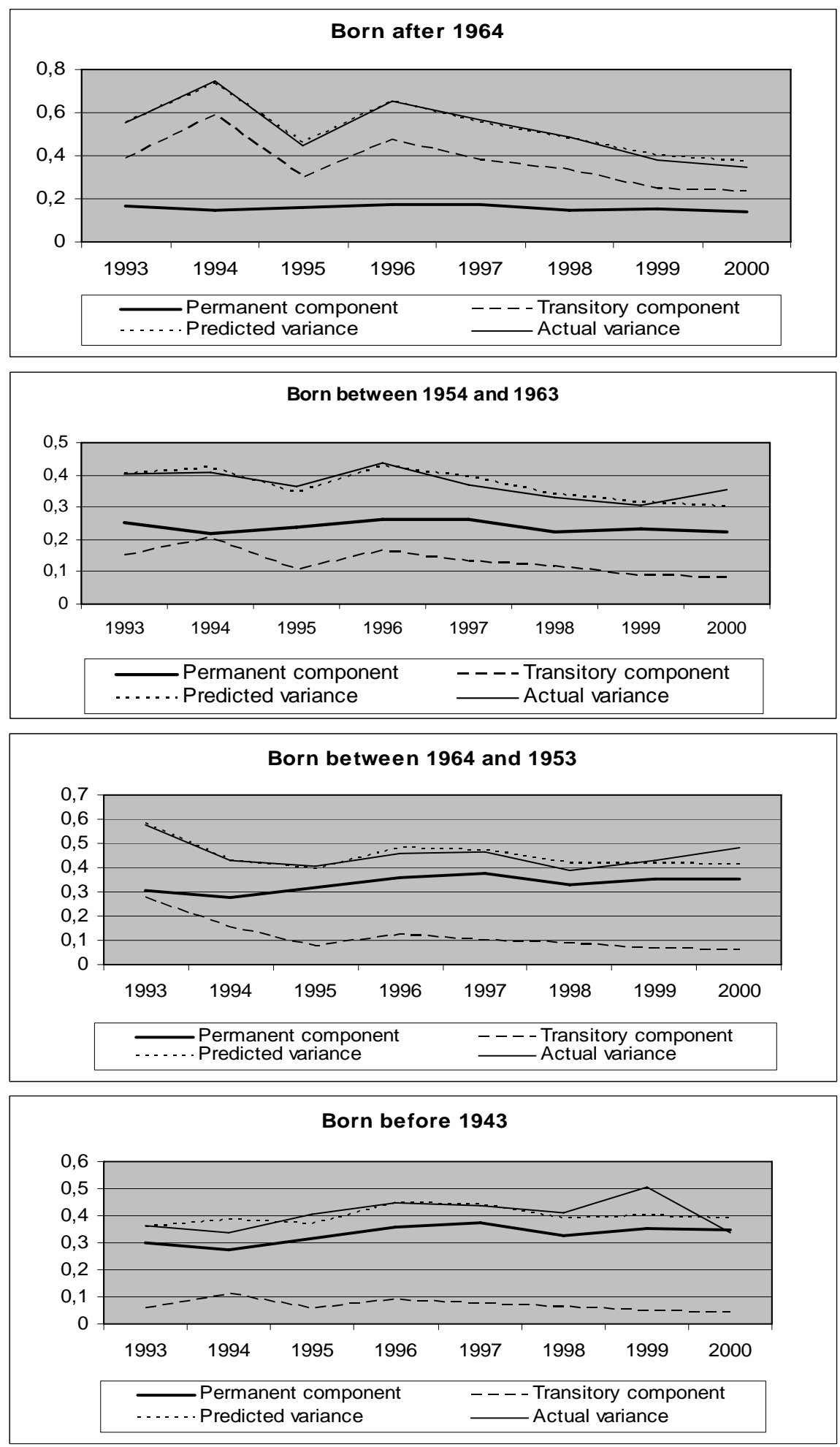
Figure 3: Predicted permanent and transitory components by cohort as percentage of predicted overall variance. $(\mathrm{RG}+\mathrm{AR}(1))$
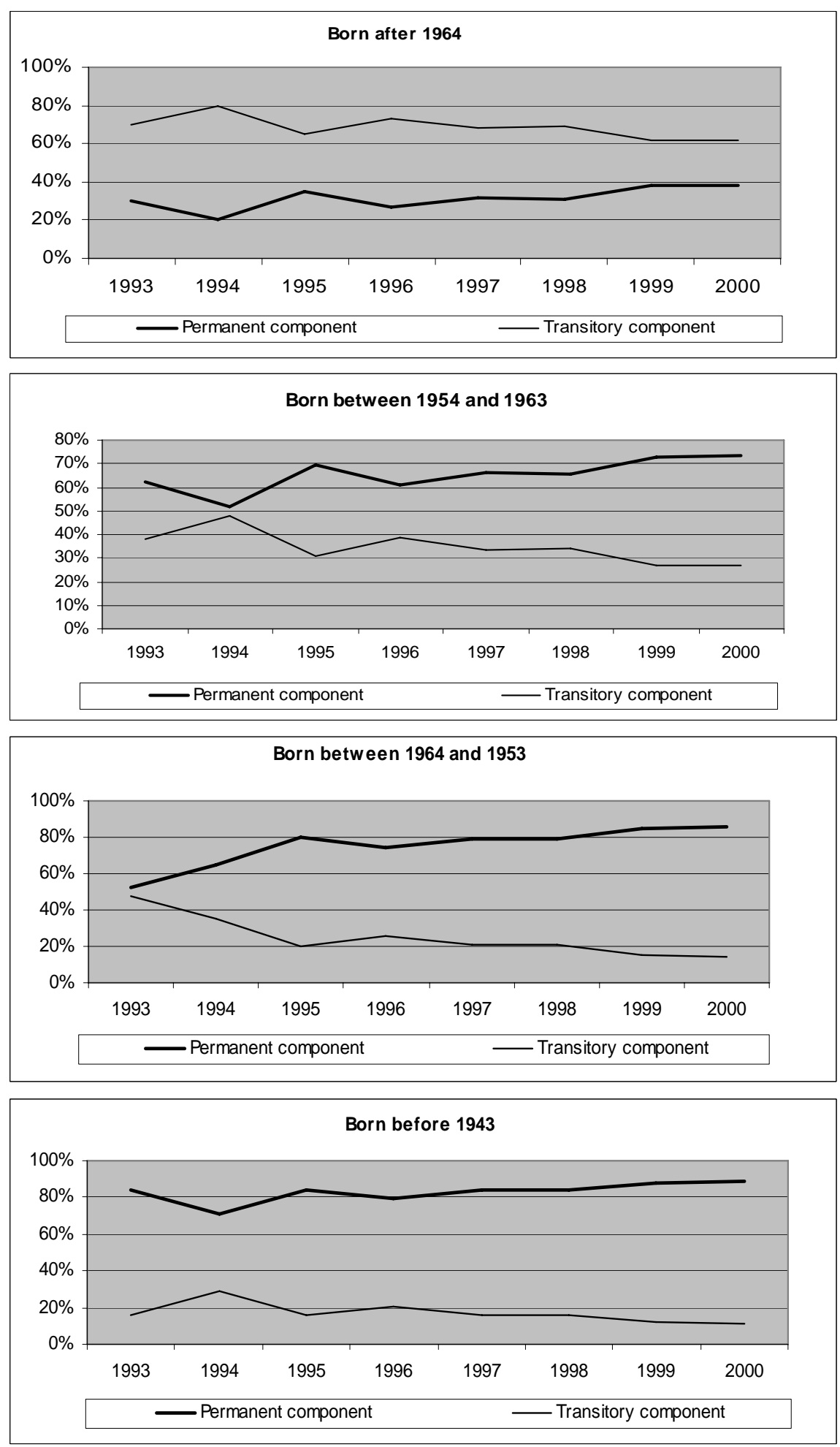
and cohort loading factors used in our model. Therefore, Table 2 shows Wald test statistics on these restrictions and reveals that such restrictions are untenable in our case.

Table 2: Wald Test of Parameter Restrictions to the Base Model

\begin{tabular}{lcc}
\hline \hline Restriction & $\chi^{2}$ & Degrees of Freedom \\
\hline$p_{95}=\ldots . .=p_{01}=0$ & 64.04 & 7 \\
$\lambda_{96}=\ldots . .=\lambda_{01}=0$ & 325.23 & 6 \\
$g_{\text {cohort } \ldots}=s_{\text {cohort ... }}=0$ & 1180.76 & 6 \\
\hline \hline
\end{tabular}

Finally, a plausible extension of our model is to supplement the autoregressive process already incorporated into the transitory component with a low degree moving average process. In terms of our estimated model, this implies replacing the AR(1) specification of equation 8 with the following $\operatorname{ARMA}(1,1)$ one:

$$
\begin{gathered}
v_{i t}=\rho_{1} v_{i t-1}+\theta_{1} \varepsilon_{i t-1}+\lambda_{t} \varepsilon_{i t} \\
\text { with } \varepsilon_{i t} \sim\left(0, \sigma_{\varepsilon}^{2}\right) \text { and } v_{i t} \sim\left(0, \sigma_{0, \text { cohort... }}^{2}\right)
\end{gathered}
$$

The estimates of this full extended model suffered from some identification problems 19 Consequently, we have restricted the initial conditions to be equal across cohorts. The results of this model are provided in the last two columns of Table 1 . The first thing to note is that the data reject the null of $\theta=0\left(\chi^{2}=15.68\right.$ and one degree of freedom). Notwithstanding this, the new ARMA specification has very little effect on the other parameter estimates -with the notable exception of $\rho$, which decreases to 0.27 - or on the decomposition of earnings inequality into its persistent and transitory components. The coefficients of the transitory $\operatorname{ARMA}(1,1)$ component are all significant, with a not very persistent AR parameter, $\rho$. Thus, the effect of a transitory shock to earnings would decline very quickly over time, with only $1 \%$ of the shock still present after 3 years. The negative MA component (-0.14) implies that the auto-covariances decline sharply over the first period.

In sum, all three models in Table 1 provide a good fit, have similar SSR and yield similar predicted permanent and transitory components.

\footnotetext{
${ }^{19}$ The model suffers from convergence problems: i.e. the model does not converge, or it converges to a solution with negative estimates of some variance.
} 


\section{The effect of temporary contracts on earnings instability}

Fixed-term or temporary contracts spread in many European countries in the Nineties as a result of changing labour market legislation (Boeri and Garibaldi (2007), Kahn (2007)), but nowhere are they as prevalent as in Spain -where temporary employment accounts for about one third of total employment.

Fixed-term or temporary employment is characterized by short job tenure and more frequent job changes (Booth, Francesconi, and Frank (2002) and Dolado, GarcaSerrano, and Jimeno (2002)). Previous evidence suggests that these two features are likely to influence earnings instability: Voluntary and involuntary (i.e. displacement) job changes are found to affect the transitory variance of earnings (Leonardi (2003), Huff-Stevens (2001)), while Cappellari and Leonardi (2006) find a negative relationship between tenure and instability.

A large literature has studied the effect of fixed-term contracts on employment, unemployment, and job flows (Kugler, Jimeno, and Hernanz (2002), Messina and Vallanti (2007)) but not much attention has been devoted to their effect on earnings instability -Cappellari and Leonardi (2006) being a notable exception. Yet, the earnings instability associated with fixed-term contracts is one of the main concerns among policy makers.

Earnings instability that results from temporary employment is also relevant as it determines individual behaviour and economic wellbeing. As long as earnings instability translates into uncertainty, the evolution of temporary employment explains also many important decisions such as emancipation or fertility (Ahn and Mira (2001)).

The previous section shows that earnings instability falls over the second half of the Nineties, and that such decrease is especially notable for the youngest cohort. At the same time, the share of temporary employment experienced the largest (relative) fall since the 1984 labour market reform, which triggered the sharp increase in temporary employment over the following decade. For our sample period, Figure 4 shows that the share of temporary employment. The evolution parallels the trend of the estimated transitory component (see Figure 2), which suggests a direct relationship between temporary employment and earnings instability.

This section explores this relationship further, and investigates whether and the 


\section{Figure 4: Percentage of Temporary Contracts in our sample}

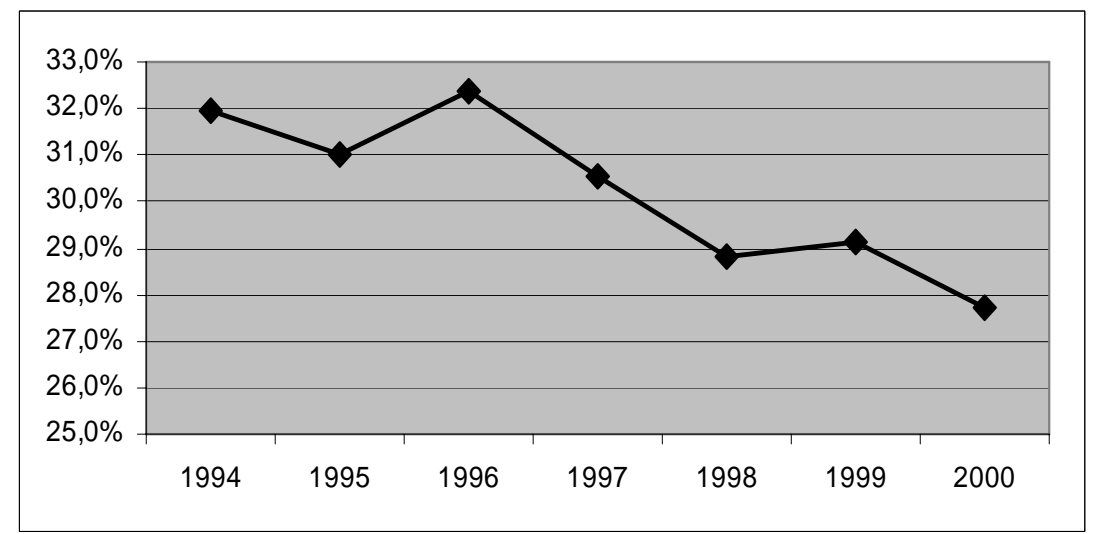

Note: We begin in the year 2004 because we do not have good information of the type of contract for the year 2003. Source: ECHP, own calculations.

extent to which the reduction in temporary employment is responsible for the reduced volatility of earnings. In particular, we estimate how much more unstable the earnings of workers on fixed-term contract are relative to those on permanent contract by modelling the effect of fixed-term contracts on the transitory and permanent components of earnings, as in Cappellari and Leonardi (2006).

To investigate the effects of temporary employment we use a stripped-down version of our preferred model (equations 7 and 8) -basically, dispensing with the random growth term-,

$$
y_{i c t}=p_{t} g_{c} \alpha_{i c}+s_{c} v_{i c t}
$$

where

$$
v_{i c t}=\rho_{1} v_{i c t-1}+\lambda_{t} \varepsilon_{i c t}
$$

and express the innovations to the permanent and transitory components as a function of the proportion of individuals on fixed-term contract

$$
\begin{gathered}
\sigma_{\alpha c t}^{2}=\delta+\gamma E\left(f_{i c t}\right) \\
\sigma_{\varepsilon c t}^{2}=\psi+\pi E\left(f_{i c t}\right)
\end{gathered}
$$

where $f_{i c t}$ indicates whether individual $i$ from cohort $c$ is on a fixed-term contract in period $t$.

Table 3 shows the results of the estimation. The negative fixed-term contract coefficient $(\gamma=-0.778)$ in the permanent component indicates that workers on temporary 
Table 3: Model of Fixed-term contract

\begin{tabular}{ccr}
\hline \hline & Coefficient & t ratio \\
\hline$\delta$ & 0.1847 & 4.38 \\
$\gamma$ & -0.7781 & -7.24 \\
$\psi$ & 0.0862 & 4.43 \\
$\pi$ & 0.3972 & 4.81 \\
$\sigma_{0,>1964}^{2}$ & 0.4095 & 5.53 \\
$\sigma_{0,54-63}^{2}$ & 0.3274 & 2.14 \\
$\sigma_{0,44-53}^{2}$ & 0.5895 & 3.86 \\
$\sigma_{0,<1943}^{2}$ & 0.0795 & 0.57 \\
$\rho$ & 0.5685 & 2.66 \\
$g_{(54-63)}$ & 1.1623 & 12.61 \\
$g_{(44-53)}$ & 1.3648 & 10.66 \\
$g_{(<1943)}$ & 1.3650 & 10.70 \\
$s_{(54-63)}$ & 0.7342 & 7.12 \\
$s_{(44-53)}$ & 0.6575 & 6.12 \\
$s_{(<1943)}$ & 0.5734 & 4.77 \\
\hline SSR $\sim \chi^{2}(d . f)$ & 348.17 & $(116)$ \\
\hline \hline
\end{tabular}

employment have on average lower long-term earnings variance relative to workers on permanent employment. Likewise, the positive coefficient $(\pi=0.397)$ in the transitory variance implies larger instability for workers on fixed-term contract relative to workers on permanent contract - which corroborates the intuition of a positive relationship between instability and temporality, obtained from the visual inspection of the trends of temporary employment and the transitory earnings component (see Figures 2 and 4). The lower permanent variance probably reflects the lower heterogeneity of workers on fixed-term contracts in terms of age, education and other observed and unobserved permanent characteristics, while the larger transitory variance picks up the effect of lower tenure and higher job mobility -among other factors that are associated with fixed-term contracts and affect earnings transitorily.

The larger instability faced by temporary workers can be clearly illustrated by comparing the predicted average transitory variance in a given year by contract type. To build such predictions we make use of the estimates of Table 3, and consider two comparison scenarios: individuals on fixed-term contract with probability given by the share of temporary employment in their cohort in a given year, and individuals who have always been on fixed-term contracts, i.e. with probability one ${ }^{20}$

\footnotetext{
${ }^{20}$ We set $\pi=0$ to predict the transitory variance of a permanent contract, weight $\pi$ by the second moment of the dummy to predict the variance of a transitory contract, and weight $\pi$ by one to predict
} 
Table 4: Predicted Transitory Variance by Contract Type

\begin{tabular}{lcccc}
\hline \hline & $\begin{array}{c}\text { Cohort born } \\
\text { after 1964 }\end{array}$ & $\begin{array}{c}\text { Cohort born } \\
1954-1963\end{array}$ & $\begin{array}{c}\text { Cohort born } \\
1964-1953\end{array}$ & $\begin{array}{c}\text { Cohort born } \\
\text { before 1943 }\end{array}$ \\
\hline Permanent & 0.0687 & 0.037 & 0.0297 & 0.0226 \\
Temporary & 0.2122 & 0.0749 & 0.0524 & 0.0424 \\
Temporary always & 0.3851 & 0.2076 & 0.1664 & 0.1266 \\
\hline \hline
\end{tabular}

We show the results of this counterfactual exercise in Table 4 broken down by cohort for the year 2000. The predicted value of the transitory variance of earnings is larger for individuals on temporary contract than for those on permanent contract, and the difference increases as we move towards the younger cohorts. Temporary contract workers can expect earnings instability which is twice as large as that for permanent workers. However, such differential is much larger for workers on temporary contracts for their entire working life, as they can expect earnings instability 5 to 6 times higher than that for workers on permanent contract. The last value changes little across cohorts.21

Thus, beyond the well documented effect of temporary contract on earnings levels (Booth, Francesconi, and Frank (2002), Davia and Hernanz (2004)) and wage growth (Amuedo-Dorantes and Serrano-Padial (2007)), our results show that the type of contract determines the dynamics of earnings, and that temporary contracts are responsible for higher earnings instability.

\section{Final remarks}

In this paper we examine whether recent earnings inequality trends in Spain were driven by changing long-term earnings inequality or were related to changes in earnings instability. Our findings suggest that the observed decline in earnings dispersion was mostly due to a fall in earnings instability. Over the course of the analyzed period (1993-2000), earnings dispersion became more persistent and much less transitory. We also show that relative earnings persistence increases over the life-cycle, which implies lower instability for older cohorts. That is, earnings instability seems to fall over the the variance of workers on temporary contracts for life.

${ }^{21}$ Our results are very much in line with those obtained by Cappellari and Leonardi (2006) for Italy. 
life cycle, being especially high for younger age groups. Our findings are in line with previous findings for some European and North American countries.

The excessively large share of temporary employment is one of the most salient features of the Spanish labour market since the mid-Eighties. Over the second half of the Nineties, several labour market reforms substantially changed important employment protection provisions and lowered payroll taxes. As a result, temporary employment experienced the largest fall since the sudden increase that followed the 1984 reform -which pushed temporary employment to account for over $30 \%$ of overall employment over the subsequent two decades. Our results suggest that the decline in temporary employment is responsible for the fall in earnings instability, which in turn accounts for most of the declining earnings inequality trend. 


\section{References}

ABowd, J., AND D. CARD (1989): "On the covariance structure of earnings and hours changes," Econometrica, 57, 411-445.

Ahn, N., And P. Mira (2001): "Job bust, baby bust: The Spanish case," Journal of Population Economics, 14(3), 505-521.

Altonji, J., And L. Segal (1996): "Small-Sample Bias in GMM Estimation of Covarinace Structure," Journal of Business and Economic Statistics, 14, 353-66.

Amuedo-Dorantes, C., And R. Serrano-Padial (2007): "Wage Growth Implications of Fixed-Term Employment: An Analysis by Contract Duration and Job Mobility," Labour Economics, 14(5), 829-847.

BAKER, M. (1997): "Growth-Rate Heterogeneity and the Covariance Structure of Life Cycle Earnings," Journal of Labour Economics, 15, 338-375.

BAKer, M., ANd G. Solon (2003): "Earning dynamics and inequality among Canadian men, 1976-1992: Evidence from longitudinal income tax record," Journal of Labour Economics, 21, 289-321.

Biewen, M. (2005): "The Covariance Structure of East and West German Incomes and its Implications for the Persistence of Poverty and Inequality," German Economic Review, $6(4), 445-469$.

Blundell, R., And I. Preston (1998): "Consumption inequality and income uncertainty," The Quarterly Journal of Economics, 113, 603-640.

Boeri, T., And P. Garibaldi (2007): "Two Tier Reforms of Employment Protection: A Honeymoon Effect?," The Economic Journal, 117, 357-385.

Booth, A., M. Francesconi, And J. Frank (2002): "Temporary Jobs: Stepping Stones or Dead Ends," The Economic Journal, 112, 189-213.

Cappellari, L. (2004): “The Dynamics and Inequality of Italian Men's Earnings: Longterm Changes or Transitory Fluctuations?," The Journal of Human Resources, 39, 475499.

CAppellari, L., AND M. Leonardi (2006): "Earnings Instability and Tenure," IZA Discussion Papers 2527, Institute for the Study of Labor (IZA).

Cutanda, A. (2002): "La medición de la desigualdad a través de un modelo de elección intertemporal," Hacienda Pública Española, 163(4/2002), 93-117.

Davia, M., And V. Hernanz (2004): "Temporary Employment and Segmentation in the Spanish Labour Market: An Empirical Analysis through the Study of Wage Differentials," Spanish Economic Review, 6, 291-318.

Dickens, R. (2000): "The Evolution of Individual Male Earnings in Grat Britain: 1975-95," The Economic Journal, 110, 27-29.

Dolado, J., C. Garca-Serrano, and J. Jimeno (2002): "Drawing Lessons from the Boom of Temporary Jobs in Spain," The Economic Journal, 112, 270-295.

HAIDER, S. (2001): "Earnings Instability and Earnings Inequality of Males in the United State: 1967-1991," Journal of Labour Economics, 19, 799-836. 
Hause, J. (1980): "The Fine Structure of Earnings and On-the-Job training hypotesis," Econometrica, 48, 1013-29.

Huff-Stevens, A. (2001): "Changes in Earnings Instability and Jobb Loss," Industrial and Labor Relations Review, 55, 60-78.

Kahn, L. M. (2007): "Employment Protection Reforms, Employment and the Incidence of Temporary Jobs in Europe: 1995-2001," IZA Discussion Papers 3241, Institute for the Study of Labor (IZA).

KalwiJ, A. S., And R. Alessie (2003): "Permanent and Transitory Wage Inequality of British Men, 1975-2001: Year, Age and Cohort Effects," IZA Discussion Papers 686, Institute for the Study of Labor (IZA).

Kugler, A., J. F. Jimeno, And V. Hernanz (2002): "Employment Consequences of Restrictive Permanent Contracts: Evidence from Spanish Labor Market Reforms," IZA Discussion Papers 657, Institute for the Study of Labor (IZA).

Leonardi, M. (2003): "Earnings Instability of Job Stayers and Job Changers," IZA Discussion Papers 946, Institute for the Study of Labor (IZA).

Lillard, L., AND Y. Weiss (1979): "Components of Variation in Panel Earnings Data: American Scientists 1960-70," Econometrica, 47, 437-455.

Lillard, L., AND R. Willis (1978): "Dynamics aspect of earnings mobility," Econometrica, 46, 985-1012.

MCCuRdy, T. H. (1982): "Dynamics aspect of earnings mobility," Journal of Econometrics, $18,83-114$.

Messina, J., and G. Vallanti (2007): "Job Flow Dynamics and Firing Restriction: Evidence from Europe," The Economic Journal, 117, 279-301.

Moffitt, R. A., and P. Gottschalk (1995): "Trends in the Variances of Permanent and Transitory Earnings in the U.S. and Their Relation to Earnings Mobility," Boston College Working Papers in Economics 444, Boston College Department of Economics.

(2002): "Trends in the Transitory Variance of Earnings in the United States," Economic Journal, 112(478), C68-C73.

Ramos, X. (2003): "The covariance structure of earnings in Great Britain, 1991-1999," Economica, 70, 353-374. 